\title{
BMJ Open Health insurance determines antenatal, delivery and postnatal care utilisation: evidence from the Ghana Demographic and Health Surveillance data
}

\author{
Joyce L Browne, ${ }^{1}$ Gbenga A Kayode, ${ }^{1}$ Daniel Arhinful, ${ }^{2}$ Samuel A J Fidder, ${ }^{1}$ \\ Diederick E Grobbee, ${ }^{1}$ Kerstin Klipstein-Grobusch ${ }^{1,3}$
}

To cite: Browne JL,

Kayode GA, Arhinful D, et al. Health insurance determines antenatal, delivery and postnatal care utilisation: evidence from the Ghana Demographic and Health Surveillance data. BMJ Open 2016;6:e008175.

doi:10.1136/bmjopen-2015008175

- Prepublication history for this paper is available online. To view these files please visit the journal online (http://dx.doi.org/10.1136/ bmjopen-2015-008175).

JLB and GAK contributed equally and are joint first authors of this work.

Received 12 March 2015 Revised 23 November 2015 Accepted 3 December 2015

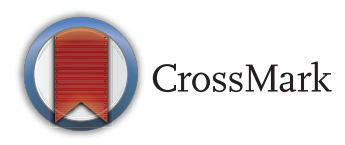

For numbered affiliations see end of article.

Correspondence to Dr Joyce L Browne; J.L.Browne@umcutrecht.nl

\section{ABSTRACT}

Objective: This study aims to evaluate the effect of maternal health insurance status on the utilisation of antenatal, skilled delivery and postnatal care.

Design: A population-based cross-sectional study. Setting and participants: We utilised the 2008 Demographic and Health Survey data of Ghana, which included 2987 women who provided information on maternal health insurance status.

Primary outcomes: Utilisation of antenatal, skilled delivery and postnatal care.

Statistical analyses: Multivariable logistic regression was applied to determine the independent association between maternal health insurance and utilisation of antenatal, skilled delivery and postnatal care.

Results: After adjusting for socioeconomic, demographic and obstetric factors, we observed that among insured women the likelihood of having antenatal care increased by $96 \%$ (OR $1.96 ; 95 \% \mathrm{Cl}$ 1.52 to $2.52 ; p$ value $<0.001$ ) and of skilled delivery by $129 \%$ (OR 2.29; $95 \%$ Cl 1.92 to 2.74 ; $p$ value $<0.001$ ), while postnatal care among insured women increased by $61 \%$ (OR $1.61 ; 95 \% \mathrm{Cl} 1.17$ to $2.21 ; p$ value $<0.01$ ). Conclusions: This study demonstrated that maternal health insurance status plays a significant role in the uptake of the maternal, neonatal and child health continuum of care service.

\section{BACKGROUND}

In the maternal, neonatal and child health $(\mathrm{MNCH})$ continuum of care, two dimensions can be identified: first, in time of care provided, ranging from preconception, antenatal, childbirth, postnatal and into childhood. Second, in place and approach of provided care, which includes both facility care as well as community-based care or household health practices. ${ }^{1}{ }^{2}$ The continuum of care model is a core principle of maternal, newborn and child healthcare and emphasises the interconnectivity and shared interests between them and reduces

\section{Strengths and limitations of this study}

- This study uses nationally representative data from a reliable data set with excellent response rates and robust sampling technique.

- This study assessed all components of the continuum of maternal, neonatal and child health.

- Limitations include that we do not have information about the quality of care provided or information about homebirths.

fragmentation in care ${ }^{1-3}$ With an estimated 292982 maternal, ${ }^{4} 2612100$ neonatal and 3662700 total under-five deaths globally, ${ }^{5}$ the continuum of care approach provides a valuable tool to identify and evaluate interventions which could reduce preventable mortality. ${ }^{67}$

In order to strengthen the continuum of care, and especially the facility-based components, strategies are needed to improve access to care and financial protection for women, babies and children. Health insurance coverage has been identified as a critical factor to improve access to and quality of maternal and perinatal care, ${ }^{6} 89$ through protection against unexpected financial setbacks, reduction of illness-associated out-of-pocket expenses and prevention of loss of employment due to prolonged illness. ${ }^{10} 11$ Globally, political commitment has been given for policies to ensure universal healthcare coverage. ${ }^{12}$ In response to the global call to implement universal health insurance coverage, the Ghanaian government established the national health insurance scheme (NHIS) under the Act of 2003. In 2011, the cumulative enrolment for national health insurance was 21.4 million; however, only 8.23 million people have active health insurance protection. ${ }^{13}$

A systematic review by Comfort et $a l^{11}$ assessed the effects of health insurance on 
the use of maternal health services and showed a generally positive association between insurance and antenatal care (ANC) attendance, ${ }^{14-21}$ facility-based delivery ${ }^{16-26}$ and skilled attendance at birth $^{16} \quad 2027$ in various sub-Saharan African (SSA), Asian, South American and Eurasian countries. This association was observed regardless of type of insurance scheme implemented, and was particularly pronounced with low baseline service utilisation. However, many studies were not based on nationally representative samples that assessed (various combinations of) components of the continuum of MNCH health. In Ghana, two regional studies did not report an effect on receipt ${ }^{14}$ of at least four ANC visits, ${ }^{14} 21$ though others did report improved attendance. ${ }^{20}$ Dixon et $a l^{28}$ evaluated the association in nationally representative data and assessed ANC care use. We add to that study by including the other components of the continuum of care services. Therefore, we aimed to assess the association between maternal health insurance status and the utilisation of the facility-based MNCH continuum of care service using nationally representative data from the Ghana Demographic and Health Survey (DHS).

\section{METHODS}

\section{Study design and data collection}

This population-based cross-sectional study used the 2008 Ghana DHS data (GDHS). Detailed information on data collection has been published elsewhere. ${ }^{29}$ In summary, a two-stage stratified cluster sampling technique was applied to identify households that were interviewed. Four hundred and twelve sampling units were selected symmetrically from the 10 regions using probability proportional sampling. A total of 6180 households, 5300 women and 5000 men were identified for interviews. All women and men of reproductive age in all the selected households, aged $15-49$ and $15-59$ years, respectively, were interviewed face to face with the aid of questionnaires (household, women's and men's questionnaires). Information on socioeconomic, demographic and health indicators was covered in questionnaires. The household, women's and men's response rates of $98.9 \%$ (6141), 96.5\% (5096) and 95.8\% (4769), respectively, were observed. ${ }^{29}$ Finally, weighting adjustment was applied, as the number of persons interviewed per sampling unit was not proportional to its population. Only those who delivered in the past 5 years (2992 women) preceding the survey were examined in this study.

\section{Outcome variables}

Three outcomes on the utilisation of continuum of care service in $\mathrm{MNCH}$ were used to assess the effect of maternal health insurance status: antenatal care, skilled delivery and postnatal care. Antenatal care was defined as care that women receive from their healthcare providers during pregnancy. Skilled delivery was defined as delivery attended by healthcare professionals (doctor, midwives and nurses) while postnatal care was defined as care that women received from their health providers postdelivery. Skilled delivery and postnatal care were coded 'yes/no' based on whether the women received it or not. Antenatal care was classified into two categories: those who had four or more antenatal visits and others who had less than four.

\section{Determinants}

Maternal health insurance status was the main determinant of interest and included both public and private insurance of participants at the time of interview. On the basis of epidemiological knowledge and prior evidence, we identified potential demographic, socioeconomic and obstetric confounding factors: maternal age, difficulty to reach the facility, maternal education, marital status, maternal occupation, wealth index, parity and multiple gestation. Wealth index was estimated by Measure DHS using an asset-based approach; household characteristics such as floor/roof type, radio, television, water source and toilet facility were operationalised using principal component analysis to generate a wealth index variable. ${ }^{29}$ Subsequently, quintiles were recoded into poor (lowest two quintiles), average (middle two quintiles) and high (highest quintile). Marital status was categorised as formerly married, currently married and never married. Maternal education was classified as no education, primary, secondary or higher education. Maternal occupation was categorised in unemployed, manual job or skilled job.

\section{Statistical analysis}

First, general descriptive statistics were calculated. Next, multivariable logistic regression analysis was used to examine the association between maternal health insurance status and the utilisation of the continuum of care service in MNCH. In the analysis, four models were fitted. Model I determined the crude association between maternal health insurance status and each of the outcomes (antenatal care, skilled delivery and postnatal care) while model II examined the association between maternal health insurance status and each of the outcomes when demographic and obstetric factors (maternal age, distance to health facility, parity and multiple gestation) were considered. Model III estimated the association between maternal health insurance status and each of the outcomes after adjusting for socioeconomic factors (maternal education, marital status, maternal occupation and wealth index). In model IV, all identified possible confounders were incorporated.

Statistical significance of the covariate was determined by two-tailed Wald test at a significance level of $\alpha$ equal to 0.05. Analyses were performed using STATA V.11 (StataCorp. Stata Statistical Software: Release 11. 2009).

\section{Ethical consideration}

Measure DHS released the data to us on request. 


\section{RESULTS}

\section{Characteristics of the study population}

General characteristics of the population are shown in table 1 . About 3000 women aged 15-49 years were interviewed. More than $90 \%$ of the women were married and $60 \%$ of them had health insurance coverage. More than half of the women lived in poverty, had two to four children and engaged in manual labour. Approximately one-third of the women had difficulty in reaching the health care facility, and two-fifths of them had no

Table 1 General characteristics of the study population, GDHS 2008

\begin{tabular}{|c|c|c|c|}
\hline \multirow[b]{2}{*}{ Characteristics } & \multirow{2}{*}{$\begin{array}{l}\text { All GDHS } \\
\text { included } \\
\text { women } \\
\text { n (\%) }\end{array}$} & \multicolumn{2}{|c|}{$\begin{array}{l}\text { Maternal health } \\
\text { insurance status }\end{array}$} \\
\hline & & $\begin{array}{l}\text { Not } \\
\text { insured } \\
\text { n (\%) }\end{array}$ & $\begin{array}{l}\text { Insured } \\
\text { n (\%) }\end{array}$ \\
\hline \multicolumn{4}{|c|}{ Socioeconomic factors } \\
\hline \multicolumn{4}{|l|}{ Marital status } \\
\hline Formerly married & $150(5)$ & $95(5.3)$ & $55(4.6)$ \\
\hline $\begin{array}{l}\text { Currently } \\
\text { married }\end{array}$ & $2712(91)$ & $1593(89.3)$ & $1114(92.7)$ \\
\hline Never married & $130(4)$ & $97(5.4)$ & $33(2.7)$ \\
\hline \multicolumn{4}{|c|}{ Maternal occupation } \\
\hline Unemployed & $300(10)$ & $193(10.8)$ & $107(9.0)$ \\
\hline Manual job & $1650(55)$ & 1055 (59.3) & $591(49.5)$ \\
\hline Skilled job & $1028(35)$ & $532(29.9)$ & 495 (41.5) \\
\hline \multicolumn{4}{|c|}{ Maternal education } \\
\hline No education & $1132(38)$ & 765 (42.9) & $362(30.1)$ \\
\hline Primary & $722(24)$ & $487(27.2)$ & 235 (19.6) \\
\hline $\begin{array}{l}\text { Secondary or } \\
\text { higher }\end{array}$ & $1138(38)$ & $533(29.9)$ & $605(50.3)$ \\
\hline \multicolumn{4}{|l|}{ Wealth Index } \\
\hline Poor & $1629(54)$ & $1116(62.5)$ & $508(42.3)$ \\
\hline Average & $504(17)$ & $296(16.6)$ & 208 (17.3) \\
\hline Rich & $859(29)$ & $373(20.9)$ & $486(40.4)$ \\
\hline \multicolumn{4}{|c|}{ Maternal health insurance } \\
\hline Yes & $1202(40)$ & & \\
\hline No & $1785(60)$ & & \\
\hline \multicolumn{4}{|c|}{ Demographic and obstetric factors } \\
\hline \multicolumn{4}{|l|}{ Maternal age (years) } \\
\hline $15-24$ & $702(23)$ & $462(25.9)$ & $240(20.0)$ \\
\hline 25-34 & $1427(48)$ & $811(45.4)$ & $613(51.0)$ \\
\hline $35-49$ & $863(29)$ & $512(28.7)$ & $349(29.0)$ \\
\hline \multicolumn{4}{|l|}{ Parity } \\
\hline 1 & $457(15)$ & $245(13.7)$ & $212(17.6)$ \\
\hline $2-4$ & $1629(55)$ & $964(54.0)$ & $665(55.3)$ \\
\hline 5 and above & $906(30)$ & 576 (32.3) & $325(27.1)$ \\
\hline \multicolumn{4}{|l|}{ Multiple gestation } \\
\hline No & $2860(96)$ & $1713(96.0)$ & $1144(95.0)$ \\
\hline Yes & $132(4)$ & $72(4.0)$ & $58(5.0)$ \\
\hline \multicolumn{4}{|c|}{ Distance from facility } \\
\hline $\begin{array}{l}\text { Difficult to } \\
\text { access }\end{array}$ & $1003(34)$ & $667(37.4)$ & $335(27.9)$ \\
\hline $\begin{array}{l}\text { Not difficult to } \\
\text { access }\end{array}$ & $1982(66)$ & $1116(62.6)$ & $866(72.1)$ \\
\hline
\end{tabular}

education. Insured women were more frequently engaged in skilled labour $(41.5 \%$ vs $29.9 \%)$, more often had completed secondary education or higher $(50.3 \%$ vs $29.9 \%$ ) and belonged to the highest quintile of wealth $(40.4 \%$ vs $20.9 \%)$. Uninsured women more often indicated having difficulty in accessing the health facility (37.4\% vs $27.9 \%)$.

\section{Association between maternal insurance and the continuum of care}

Table 2 shows the results of the multivariable logistic regression that examined the association between maternal health insurance status and the utilisation of antenatal care, delivery and postnatal care services.

The crude association was estimated in model I; the likelihood of attending at least four antenatal clinics increased by 2.7-fold (OR 2.71; 95\% CI 2.13 to 3.44) among women who were insured. This estimate declined to 2.4-fold (OR 2.40; 95\% CI 1.88 to 3.06) and 2.0-fold (OR 2.03; 95\% CI 1.58 to 2.61 ) when adjusted for socioeconomic factors in model II and demographic and obstetric factors in model III, respectively. After fully adjusting for socioeconomic, demographic and obstetric factors in model IV, the probability of attending four or more antenatal clinics among women who were insured was nearly twofold (OR 1.96; 95\% CI 1.52 to 2.52) compared to those who were not insured.

The unadjusted association between maternal health status and skilled delivery was considered in model I; the odds of having a skilled delivery among women who were insured increased threefold (OR 3.18; 95\% CI 2.72 to 3.72). When socioeconomic factors were accounted for in model II, and demographic and obstetric factors were considered in model III, the crude association declined to 2.9 (OR 2.89; 95\% CI 2.45 to 3.40) and 2.4 (OR 2.37; 95\% CI 1.98 to 2.83), respectively. In model IV, socioeconomic, demographic and obstetric factors were accounted for and the odds of insured pregnant women having a skilled delivery remained statistically significant. The likelihood of having a skilled delivery among pregnant women who were insured was more than double (OR 2.29; 95\% CI 1.91 to 2.74) compared to those uninsured.

The unadjusted association between maternal health insurance status and the uptake of postnatal care service was evaluated in model I; the likelihood of attending postnatal clinic increased by $63 \%$ (OR 1.63; 95\% CI 1.20 to 2.23). After incorporating socioeconomic factors in model II and adjusting for demographic and obstetric factors in model III, the probability of attending postnatal clinics was only slightly altered (OR $1.59 ; 1.16$ to 2.18 for model II and OR $1.65 ; 1.20$ to 2.25 for model III, respectively). Socioeconomic, demographic and obstetric factors were considered in model IV showing the probability of attending postnatal clinics among insured women to be $61 \%$ higher (OR 1.61; 95\% CI 1.17 to 2.21 ) compared to uninsured women. 
Table 2 Association between maternal health insurance status and antenatal, delivery and postnatal care utilisation, GDHS 2008

\begin{tabular}{|c|c|c|c|c|}
\hline & Model I & Model II & Model III & Model IV \\
\hline \multicolumn{5}{|c|}{ Antenatal care utilisation ORs $(95 \% \mathrm{Cl})$} \\
\hline Insured & $2.71(2.13 \text { to } 3.44)^{\star \star \star}$ & $2.40(1.88 \text { to } 3.06)^{\star \star \star}$ & $2.03(1.58 \text { to } 2.61)^{\star * *}$ & $1.96(1.52 \text { to } 2.52)^{\star \star \star}$ \\
\hline Not insured & 1 (reference) & 1 (reference) & 1 (reference) & 1 (reference) \\
\hline \multicolumn{5}{|c|}{ Delivery care utilisation ORs $(95 \% \mathrm{Cl})$} \\
\hline Insured & $3.18(2.72 \text { to } 3.72)^{\star \star \star}$ & $2.89(2.45 \text { to } 3.40)^{\star \star \star}$ & $2.37(1.98 \text { to } 2.83)^{\star \star *}$ & $2.29(1.91 \text { to } 2.74)^{\star \star \star}$ \\
\hline Not insured & 1 (reference) & 1 (reference) & 1 (reference) & 1 (reference) \\
\hline \multicolumn{5}{|c|}{ Postnatal care utilisation ORs $(95 \% \mathrm{Cl})$} \\
\hline Insured & $1.63(1.20 \text { to } 2.23)^{\star \star}$ & $1.59(1.16 \text { to } 2.18)^{\star \star}$ & $1.65(1.20 \text { to } 2.25)^{\star \star}$ & $1.61(1.17 \text { to } 2.21)^{\star \star}$ \\
\hline Not insured & 1 (reference) & 1 (reference) & 1 (reference) & 1 (reference) \\
\hline
\end{tabular}

\section{DISCUSSION}

\section{Main findings}

The findings in this study show that maternal health insurance status plays a significant role in the utilisation of MNCH continuum of care services. Insured women had a better uptake of antenatal care, skilled delivery and postnatal care than those who were not insured regardless of differences in socioeconomic, demographic and obstetric characteristics.

Our findings are in line with previous studies reporting that maternal health insurance enhances the continuum of $\mathrm{MNCH}$ care utilisation. ${ }^{11} \mathrm{~A}$ number of previous studies have explored the association between insurance status and $\mathrm{MNCH}$ services utilisation in Ghana. Two regional studies by Chankova et $a l^{14}$ and Smith and Sulzbach ${ }^{21}$ did not report an effect on receipt of at least four ANC visits. Dixon $e t a l^{28}$ used nationally representative data of GDHS and observed a higher frequency of ANC care use among NHIS enrolled women, although the timing of the first ANC visit did not differ. Likewise, Amoakoh-Coleman et $a \hat{l}^{0}$ showed with GDHS data that insured women were more likely to have skilled delivery. We add to the available evidence by including the other components of the continuum of care services. Similarly, the observations by Mensah et $a l,{ }^{20}$ who reported improvements in attendance on the continuum of care in two administrative districts in Ghana, and Dzakpasu et al, ${ }^{31}$ who showed better facility delivery rates after the implementation of free delivery care in 2003/2005 and in 2008 after the NHIS fee exemption scheme had been established, are consistent with our findings. The latter study also suggested that insurance may reduce inequities, as the poor benefited especially. This is of relevance in the light of the persistent inequities in maternal health. ${ }^{32} 33$

This GDHS study is the most recent one available and was conducted before the implementation of the broader fee exemption scheme for pregnant women in Ghana. From 1 July 2008 onwards, pregnant women were eligible under the exemption scheme to enrol within the NHIS without registration and premium fees to receive up to six ANC visits, delivery, two postnatal visits within 6 weeks after delivery and care of the newborn up to 3 months. ${ }^{20}$ Until then, only delivery was free of charge. ${ }^{28}$ Importantly, even during the fee exemption scheme, care is often not completely free due to associated, out-of-pocket, expenses such as transportation or medicines not covered under the scheme. Furthermore, the maternal health insurance package did not include family planning services and products, except for counselling postnatal women. Any products required had to be secured outside the insurance package. Reduction of health-associated expenses would most likely further improve the continuum of care services for poor women. ${ }^{34} 35$

The strength of our study is that we use nationally representative data and assessed all components of the continuum of care. The GDHS data are perceived as reliable data considering their excellent individual and household response rates and robust sampling technique. ${ }^{29}$ Limitations include that we do not have information on the quality of care provided. As such, we cannot establish a causal link with health outcomes, which has previously been described as an inherent difficulty of insurance association studies. ${ }^{36}$ Also, most maternal, newborn and child deaths occur at home and may be missed or underreported in the GDHS, requiring additional efforts to assess the magnitude of births at home with respect to continuum of care under maternal health insurance. Since only surviving mothers have the opportunity to be interviewed in the GDHS data, underestimation of the observed associations might be possible if those who died during delivery were uninsured women without antenatal, skilled delivery and postnatal care.

Utilisation of MNCH care in itself does not guarantee a sufficient quality of care, and the evidence by which health insurance affects quality of care is inconclusive. ${ }^{11}$ In Ghana, Mensah et al reported that NHIS members, that is, those with health insurance, were not more likely to have blood pressure measurements or blood and 
urine analyses performed during antenatal care. ${ }^{20}$ In contrast, in Brazil, health insurance was associated with a higher likelihood of having routine blood and urine tests, ultrasounds and vitamin and iron prescription. ${ }^{37}$ It was also reported that health insurance does not necessarily improve the timeliness of the essential first ANC visit. ${ }^{28}$ An evaluation of the free delivery policy implemented before the maternal health insurance policy in Ghana noted that women's care-seeking behaviour in some cases is unlikely to change under the free delivery policy because of negative experiences, perceptions and/or misconceptions about the policy and the fact that there may still be additional costs associated with the use of health services. ${ }^{38}$ Efforts to improve the continuum of care require a holistic approach to improve the supply and demand sides of care, and our findings will inform health policymakers that implementing universal health insurance is one of the main interventions to ensure access to $\mathrm{MNCH}$ continuum of care regardless of demographic, obstetrics and socioeconomic differences among women and their children.

\section{CONCLUSION}

The result of this study using data on a representative sample of 2987 pregnant women provides strong support that health insurance coverage of pregnant women promotes the uptake of maternal neonatal and child continuum of care service.

\author{
Author affiliations \\ ${ }^{1} J u l i u s$ Global Health, Julius Centrum for Health Sciences and Primary Care, \\ University Medical Center Utrecht, Utrecht, The Netherlands \\ ${ }^{2}$ Noguchi Memorial Institute of Medical Research, University of Ghana, Accra, \\ Ghana \\ ${ }^{3}$ Division of Epidemiology \& Biostatistics, School of Public Health, Faculty of \\ Health Sciences, University of the Witwatersrand, Johannesburg, South Africa
}

Twitter Follow Joyce Browne at @JoyceBrowne

Acknowledgements The authors are grateful to Measures DHS for permitting them to utilise the GDHS data set.

Contributors JLB, GAK and KK-G conceptualised and designed the study. JLB and GAK carried out the literature review, data extraction and analysis and drafted the first version of the manuscript. All authors (JLB, GAK, KK-G, DA, SAJF and DEG reviewed and approved the final version of the manuscript.

Funding The authors appreciate the financial support of the Netherlands Scientific Organization for Scientific Research, WOTRO Science for Global Development (Grant number W07.45.102.00) to GAK towards the accomplishment of the study.

Competing interests None declared.

Ethics approval Ethics Review Committee, Ghana Health Service, Accra, Ghana and the Ethics Committee of ICF Macro in Calverton, USA gave the ethical approval to conduct GDHS.

Provenance and peer review Not commissioned; externally peer reviewed.

Data sharing statement The data set is available by emailing the corresponding author.

Open Access This is an Open Access article distributed in accordance with the Creative Commons Attribution Non Commercial (CC BY-NC 4.0) license, which permits others to distribute, remix, adapt, build upon this work non- commercially, and license their derivative works on different terms, provided the original work is properly cited and the use is non-commercial. See: http:// creativecommons.org/licenses/by-nc/4.0/

\section{REFERENCES}

1. De Graft-Johnson J, Kerber K, Tinker A, et al. The maternal, newborn and child health continuum of care. In: Lawn J, Kerber K, eds. Opportunities for Africa's newborns. Cape Town, South Africa: WHO on behalf of The Partnership for Maternal Newborn and Child Health, 2006:23-36.

2. Kerber KJ, de Graft-Johnson JE, Bhutta ZA, et al. Continuum of care for maternal, newborn, and child health: from slogan to service delivery. Lancet 2007;370:1358-69.

3. Tinker A, ten Hoope-Bender P, Azfar S, et al. A continuum of care to save newborn lives. Lancet 2005;365:822-5.

4. Kassebaum NJ, Bertozzi-Villa A, Coggeshall MS, et al. Global, regional, and national levels and causes of maternal mortality during 1990-2013: a systematic analysis for the Global Burden of Disease Study 2013. Lancet 2014;384:980-1004.

5. Wang $\mathrm{H}$, Liddell CA, Coates MM, et al. Global, regional, and national levels of neonatal, infant, and under-5 mortality during 1990-2013: a systematic analysis for the Global Burden of Disease Study 2013. Lancet 2014;384:957-79.

6. Bhutta ZA, Das JK, Bahl R, et al. Can available interventions end preventable deaths in mothers, newborn babies, and stillbirths, and at what cost? Lancet 2014;384:347-70.

7. Mangham-Jefferies L, Pitt C, Cousens S, et al. Cost-effectiveness of strategies to improve the utilization and provision of maternal and newborn health care in low-income and lower-middle-income countries: a systematic review. BMC Pregnancy Childbirth 2014;14:243.

8. Dickson KE, Simen-Kapeu A, Kinney MV, et al. Every newborn health-systems bottlenecks and strategies to accelerate scale-up in countries. Lancet 2014;384:438-54.

9. Ensor T, Cooper S. Overcoming barriers to health service access: influencing the demand side. Health Policy Plan 2004;19:69-79.

10. Alam K, Mahal A. Economic impacts of health shocks on households in low and middle income countries: a review of the literature. Global Health 2014;10:21.

11. Comfort AB, Peterson LA, Hatt LE. Effect of health insurance on the use and provision of maternal health services and maternal and neonatal health outcomes: a systematic review. J Health Popul Nutr 2013;31(4 Suppl 2):81-105.

12. UN General Assembly. Resolution adopted by the General Assembly on 12 December 2012. Global health and foreign policy A/RES/67/81. http://www.un.org/en/ga/search/view_doc.asp? symbol=A/RES/67/81; 2012. New York: United Nations.

13. Owusu-Sekyere E, Chiaraah A. Demand for health insurance in Ghana: what factors influence enrollment? Am J Public Heal Res 2014;2:27-35

14. Chankova S, Atim C, Hatt L. Ghana's national health insurance scheme. In: Escobar M, Griffin CC, Shaw RP, eds. The impact of health insurance in low- and middle-income countries. Washington, DC: Brookings Insitution Press, 2010:58-88.

15. Celik Y, Hotchkiss DR. The socio-economic determinants of maternal health care utilization in Turkey. Soc Sci Med 2000;50:1797-806.

16. Bogg L, Wang K, Diwan V. Chinese maternal health in adjustment: claim for life. Reprod Health Matters 2002;10:95-107.

17. Schneider P, Diop F. Impact of prepapyment pilot on health care utilization and financing in Rwanda: findings from final household survey. Bethesda, MD: The Partners for Health Reformplus Project, Abt Associates Inc, 2001.

18. Adinma ED, Brian-D Adinma JI, Obionu CC, et al. Effect of government-community healthcare co-financing on maternal and child healthcare in Nigeria. West Afr J Med 2011;30:35-41.

19. Adinma ED, Nwakoby BAN, Briad-D Adinma Jl. Integrating maternal health services into a health insurance scheme: effect on healthcare delivery. Nig Q J Hosp Med 2010;20:86-93.

20. Mensah J, Oppong JR, Schmidt CM. Ghana's National Health Insurance scheme in the context of the health MDGs: an empirical evaluation using propensity score matching. Health Econ 2010;19 (Suppl):95-106.

21. Smith KV, Sulzbach S. Community-based health insurance and access to maternal health services: evidence from three West African countries. Soc Sci Med 2008;66:2460-73.

22. Cutler DM, Zeckhauser RJ. The anatomy of health insurance. In: Culyer A, Newhouse J, eds. Handbook of health economics. Oxford: Elsevier, 2000:564-637. 
23. Aggarwal A. Impact evaluation of India's 'Yeshasvini' community-based health insurance programme. Health Econ 2010;19(Suppl):5-35

24. Devadasan N, Criel B, Van Damme W, et al. Community health insurance in Gudalur, India, increases access to hospital care. Health Policy Plan 2010;25:145-54.

25. McQuestion MJ, Velasquez A. Evaluating program effects on institutional delivery in Peru. Health Policy 2006;77:221-32.

26. Sekabaraga C, Diop F, Soucat A. Can innovative health financing policies increase access to MDG-related services? Evidence from Rwanda. Health Policy Plan 2011;26(Suppl 2):ii52-62.

27. Renaudin $\mathrm{P}$, Prual $\mathrm{A}$, Vangeenderhuysen $\mathrm{C}$, et al. Ensuring financia access to emergency obstetric care: three years of experience with obstetric risk insurance in Nouakchott, Mauritania. Int J Gynaecol Obstet 2007;99:183-90.

28. Dixon J, Tenkorang EY, Luginaah IN, et al. National health insurance scheme enrolment and antenatal care among women in Ghana: is there any relationship? Trop Med Int Health 2014;19:98-106.

29. Ghana Statistical Services (GSS), Ghana Health Services (GHS), ICF Macro (2009). Ghana demographic and health survey 2008. Accra, Ghana: GSS, GHS, and ICF Macro, 2009.

30. Amoakoh-Coleman M, Ansah EK, Agyepong IA, et al. Predictors of skilled attendance at delivery among antenatal clinic attendants in Ghana: a cross-sectional study of population data. BMJ Open 2015;5:e007810.
31. Dzakpasu S, Soremekun S, Manu A, et al. Impact of free delivery care on health facility delivery and insurance coverage in Ghana's Brong Ahafo Region. PLOS ONE 2012;7:e49430.

32. Boerma JT, Bryce J, Kinfu Y, et al. Mind the gap: equity and trends in coverage of maternal, newborn, and child health services in 54 countdown countries. Lancet 2008;371:1259-67.

33. Målqvist $\mathrm{M}$, Yuan $\mathrm{B}$, Trygg $\mathrm{N}$, et al. Targeted interventions for improved equity in maternal and child health in low- and middle-income settings: a systematic review and meta-analysis. PLOS ONE 2013;8:e66453.

34. Finlayson K, Downe S. Why do women not use antenatal services in low- and middle-income countries? A meta-synthesis of qualitative studies. PLoS Med 2013;10:e1001373.

35. Addai I. Determinants of use of maternal-child health services in rural Ghana. J Biosoc Sci 2000;32:1-15.

36. Mensah J, Oppong J. Maternity protections and health insurance in Africa: comparative overview of Ghana, Kenya, Rwanda, and Tanzania. External collaboration report for the Social Security Department of the International Labour Office. Geneva, 2007.

37. Victora CG, Matijasevich A, Silveira M, et al. Socio-economic and ethnic group inequities in antenatal care quality in the public and private sector in Brazil. Health Policy Plan 2010;25:253-61.

38. Armar-Klemesu M, Arhinful D, Aikins M, et al. An evaluation of Ghana's policy of universal fee exemption for delivery care: preliminary findings. Immpact, University of Aberdeen, 2006. 